Check for updates

Cite this: RSC Adv., 2017, 7, 49518

\title{
Titania-coated gold nanorods as an effective carrier for gambogic acid $\dagger$
}

\author{
Hong-Ye Wan, (D) Jian-Li Chen, Xiao-Yan Yu and Xiao-Ming Zhu (DD *
}

Gambogic acid (GA), a natural product, exhibits potent anticancer effects. Unfortunately, further clinical application of this drug is limited by its poor solubility in aqueous solutions. In the present study, titanium dioxide $\left(\mathrm{TiO}_{2}\right)$-coated gold nanorod $\left(\mathrm{GNR} / \mathrm{TiO}_{2}\right)$ nanostructures were used as a carrier for $\mathrm{GA}$. The GNR/ $\mathrm{TiO}_{2}$ nanostructure-based delivery was found to provide a stable aqueous dispersion of GA. Compared with the free form, enhanced intracellular GA delivery was achieved by using the $\mathrm{GNR} / \mathrm{TiO}_{2}$ nanostructures. An in vitro cytotoxicity study indicated that the $\mathrm{GA}$-loaded $\mathrm{GNR} / \mathrm{TiO}_{2}$ nanostructures were much more effective in inhibiting the proliferation of human glioblastoma U-87 MG cells than free $\mathrm{GA}$, particularly at lower working concentrations. Furthermore, the $\mathrm{GNR} / \mathrm{TiO}_{2}$ nanostructures displayed a high photothermal conversion efficiency, and irradiation at a low dose $\left(5.3 \mathrm{~W} \mathrm{~cm}^{-2}, 2 \mathrm{~min}\right)$ with an $808 \mathrm{~nm}$ laser also synergistically enhanced the anticancer effect of the GA-loaded $\mathrm{GNR} / \mathrm{TiO}_{2}$ nanostructures. Therefore, our results suggest that $\mathrm{GNR} / \mathrm{TiO}_{2}$ nanostructure-based drug delivery is a promising method to improve the therapeutic efficacy of GA.

Received 3rd August 2017

Accepted 13th October 2017

DOI: $10.1039 / \mathrm{c} 7 \mathrm{ra0} 8560 \mathrm{e}$

rsc.li/rsc-advances treating metastatic breast cancer. ${ }^{10,11}$ Recently, Cremophor EL, ${ }^{12}$ chitosan, ${ }^{13}$ polyethylene glycol (PEG) ${ }^{14}$ lipoproteins, ${ }^{15}$ and dendrimers, ${ }^{12}$ have been used as drug-delivery vehicles for GA. However, these drug-delivery systems still have some drawbacks. For example, Cremophor EL has several side effects including cardiotoxicity, nephrotoxicity, neurotoxicity, and hypersensitivity reactions. ${ }^{16}$ Therefore, developing novel delivery systems for GA is essential.

Recently, gold nanostructures have attracted much attention for their applications in cancer diagnosis and therapy. ${ }^{\mathbf{1 7 - 1 9}}$ Among various gold nanostructures, gold nanorods (GNRs) are widely studied due to their unique plasmonic properties. Their localized surface plasmon resonance (LSPR) can be easily tuned to the near-infrared (NIR) region, and this property makes GNRs a candidate agent for in vivo imaging and therapy, ${ }^{19,20}$ as light in the NIR region can penetrate deeply into tissues. ${ }^{21}$ When irradiated with an NIR laser, GNRs are able to convert light energy into heat, which induces cancer cell death. GNRs show great potential for cancer photothermal therapy. When GNRs serve as anticancer drug carriers, the heat can trigger anticancer drug release or enhance the cytotoxicity. ${ }^{22-24}$

Titanium dioxide $\left(\mathrm{TiO}_{2}\right)$ nanoparticles have many important applications in solar cells ${ }^{25}$ and photocatalysis. ${ }^{26} \mathrm{TiO}_{2}$ shows a high binding affinity to carboxylic acids, and the types of binding exhibited by carboxylic groups on $\mathrm{TiO}_{2}$ include simple adsorption (electrostatic attraction and hydrogen bonding) and chemical adsorption (ester linkage, bridging, and chelating). ${ }^{27}$ In this study, $\mathrm{TiO}_{2}$-coated GNR $\left(\mathrm{GNR} / \mathrm{TiO}_{2}\right)$ nanostructures were firstly reported as a drug carrier for GA, as the GA molecule has a carboxylic acid group. The anticancer effect of GA-loaded
State Key Laboratory of Quality Research in Chinese Medicine, Macau Institute for Applied Research in Medicine and Health, Macau University of Science and Technology, Taipa, Macau, China.E-mail: xmzhu@must.edu.mo

$\dagger$ Electronic supplementary information (ESI) available. See DOI: 10.1039/c7ra08560e 
$\mathrm{GNR} / \mathrm{TiO}_{2}$ nanostructures was compared with that of the free drug. In addition, the synergistic anticancer effect of $\mathrm{GNR} / \mathrm{TiO}_{2}$ nanostructure-based photothermal therapy and GA was investigated.

\section{Experimental}

\subsection{Preparation of the GNR nanostructures}

A cetyltrimethylammonium bromide (CTAB)-capped GNR (GNR/CTAB) sample was prepared through a seed-mediated growth method. ${ }^{28}$ Briefly, the seed solution was made by adding a freshly prepared, ice-cold $\mathrm{NaBH}_{4}$ solution $(0.01 \mathrm{M}, 0.6 \mathrm{~mL})$ into a mixture of $\mathrm{HAuCl}_{4}(0.01 \mathrm{M}, 0.25 \mathrm{~mL})$ and CTAB $(0.1 \mathrm{M}$, $9.75 \mathrm{~mL}$ ). The resultant seed solution was kept at room temperature for $2 \mathrm{~h}$ before use. The CTAB growth solution was prepared by the sequential addition of $\mathrm{HAuCl}_{4}(0.01 \mathrm{M}, 2 \mathrm{~mL})$, $\mathrm{AgNO}_{3}(0.01 \mathrm{M}, 0.4 \mathrm{~mL}), \mathrm{HCl}(1.0 \mathrm{M}, 0.8 \mathrm{~mL})$ and ascorbic acid $(0.1 \mathrm{M}, 0.32 \mathrm{~mL})$ into the CTAB solution $(0.1 \mathrm{M}, 40 \mathrm{~mL})$. After the solution was well mixed, the seed solution $(40 \mu \mathrm{L})$ was rapidly added into the growth solution. The resultant solution was mixed by stirring for $30 \mathrm{~s}$ and was then kept at $30^{\circ} \mathrm{C}$ overnight. After centrifugation $(7000 \mathrm{~g}, 10 \mathrm{~min})$, the obtained pellet was redispersed in deionized water $(40 \mathrm{~mL})$.

\subsection{Preparation of the $\mathrm{GNR} / \mathrm{TiO}_{2}$ nanostructures}

$\mathrm{GNR} / \mathrm{TiO}_{2}$ nanostructures were prepared as described in a previous report. ${ }^{28}$ The CTAB-capped GNRs were first coated with poly(sodium 4-styrenesulfonate) (PSS). Briefly, the CTAB-capped GNR solution $(10 \mathrm{~mL})$ was added dropwise into a PSS solution (molecular weight at $70000,2 \mathrm{~g} \mathrm{~L}^{-1}, 6 \mathrm{mM} \mathrm{NaCl}, 10 \mathrm{~mL}$ ) followed by stirring for $6 \mathrm{~h}$. The excess PSS was removed by centrifugation $(7000 \mathrm{~g}, 10 \mathrm{~min})$ twice, and the resultant pellet was redispersed into deionized water $(0.2 \mathrm{~mL})$. Then, a $\mathrm{TiCl}_{3}$ solution $(15 \mathrm{wt} \%$, $0.2 \mathrm{~mL}$, containing $20-30 \mathrm{wt} \% \mathrm{HCl}$ ) was added into deionized water $(6 \mathrm{~mL})$ under stirring, followed by the dropwise addition of $\mathrm{NaHCO}_{3}(0.93 \mathrm{M}, 1.35 \mathrm{~mL})$ and immediate addition of the concentrated GNR/PSS solution $(0.2 \mathrm{~mL})$ into the mixture. After stirring for $30 \mathrm{~min}$, the produced $\mathrm{GNR} / \mathrm{TiO}_{2}$ nanostructures were precipitated by centrifugation $(6000 \mathrm{~g}, 10 \mathrm{~min})$ and redispersed in deionized water $(10 \mathrm{~mL})$.

\subsection{Nanostructure characterization}

The extinction spectrum of the nanostructures was measured using a Hitachi U-3501 UV/visible/NIR spectrophotometer. The sizes and shapes of the synthesized nanostructures were characterized using an FEI Tecnai F20 microscope at $120 \mathrm{kV}$. The zeta potential and hydrodynamic size of the nanostructures were determined with a Malvern Zetasizer Nano ZS90 analyzer in deionized water. The concentration of the $\mathrm{GNR} / \mathrm{TiO}_{2}$ nanostructures was measured by an Agilent inductively coupled plasma mass spectrometry (ICP-MS) 7500a system.

\subsection{Determination of the photothermal conversion} efficiency

An aqueous $\mathrm{GNR} / \mathrm{TiO}_{2}$ nanostructure solution $(2 \mathrm{~mL})$, with the optical density at $808 \mathrm{~nm}$ adjusted to 2.0 , in a $1 \mathrm{~cm}$ square quartz cuvette was irradiated with an NIR laser (808 nm) at different power intensities $(0.6,1.0$, or $1.4 \mathrm{~W})$ for $30 \mathrm{~min}$. The temperature of the solution was measured with a digital thermometer every $30 \mathrm{~s}$. The probe of the thermometer was placed at such a position that the direct irradiation of the laser on the probe head was avoided. A cooling curve was obtained after the laser was switched off. The photothermal conversion efficiency was determined using a previously reported method. ${ }^{29}$

\subsection{Cell culture}

Human glioblastoma U-87 MG cells were obtained from American Type Culture Collection (ATCC, Manassas, VA, USA), and were cultured in alpha-modified Minimum Essential Medium ( $\alpha$-MEM, Thermo Fisher Scientific, Waltham, MA, USA) containing $10 \%$ fetal bovine serum (FBS), $100 \mathrm{U} \mathrm{mL}^{-1}$ penicillin and $100 \mu \mathrm{g} \mathrm{mL}{ }^{-1}$ streptomycin at $37{ }^{\circ} \mathrm{C}$ in a humidified $5 \% \mathrm{CO}_{2}$ atmosphere.

\subsection{Cell viability assay}

A CellTiter-Glo luminescent cell viability assay kit (Promega Corporation, Madison, WI, USA) was used to evaluate the cell viability. This is a homogeneous method to determine the number of viable cells, based on quantifying the adenosine triphosphate (ATP) present, which represents the presence of metabolically active cells. U-87 MG cells were seeded in the wells of a 96-well plate at a density of $5 \times 10^{3}$ cells per well in $100 \mu \mathrm{L}$ $\alpha$-MEM. After incubation for $12 \mathrm{~h}$, the medium in the wells was replaced with a fresh medium containing $\mathrm{GNR} / \mathrm{TiO}_{2}$ nanostructures, GA or GA-loaded $\mathrm{GNR} / \mathrm{TiO}_{2}$ nanostructures. After incubation for $48 \mathrm{~h}$, the cells were washed with phosphate buffered saline (PBS), and a fresh medium $(100 \mu \mathrm{L})$ was added into each well. CellTiter-Glo reagent $(100 \mu \mathrm{L})$ was then added to the wells, followed by shaking for $2 \mathrm{~min}$ on an orbital shaker. After further incubation for $10 \mathrm{~min}$ at room temperature to allow for stabilization of the luminescent signals, the solution from the wells was centrifuged $(10000 \mathrm{~g}, 10 \mathrm{~min})$. The collected supernatant $(180 \mu \mathrm{L})$ was then transferred into each well of a 96-well white plate, and the luminescent signals were detected using a Molecular Devices SpectraMax Paradigm multi-mode microplate reader. The cell viability (\%) was calculated for each sample relative to a control.

\subsection{Cellular uptake observations}

Eight thousand cells were seeded into each well of a 24 -well plate. After incubation for $12 \mathrm{~h}$, the culture medium was replaced with a fresh medium containing the $\mathrm{GNR} / \mathrm{TiO}_{2}$ nanostructures $\left(30 \mu \mathrm{g} \mathrm{Au} \mathrm{mL}{ }^{-1}, 0.5 \mathrm{~mL}\right)$. After the cells were further incubated for $24 \mathrm{~h}$, they were washed with PBS extensively to remove any nanoparticles adsorbed on the cell surface. The cellular uptake of the $\mathrm{GNR} / \mathrm{TiO}_{2}$ nanostructures was observed using an Olympus IX71 microscope under bright field.

\subsection{Drug loading}

The GNR/ $/ \mathrm{TiO}_{2}$ nanostructures $\left(750 \mu \mathrm{g} \mathrm{Au} \mathrm{mL}{ }^{-1}, 0.1 \mathrm{~mL}\right)$ were centrifuged $(6000 \mathrm{~g}, 5 \mathrm{~min})$ and washed with ethanol $(0.2 \mathrm{~mL})$. 
After centrifugation, the resulting pellet was redispersed in a $0.1 \mathrm{~mL}$ ethanol solution containing GA $(200 \mu \mathrm{M}$, SigmaAldrich, St. Louis, MO, USA), followed by overnight stirring. The GA-loaded GNR/TiO ${ }_{2}$ nanostructures were then obtained by centrifugation, and dispersed in the medium $(0.1 \mathrm{~mL})$ for further cell studies.

\subsection{Drug loading capacity calculations}

After centrifugation $(6000 \mathrm{~g}, 10 \mathrm{~min})$, the pellet of the GA-loaded $\mathrm{GNR} / \mathrm{TiO}_{2}$ nanostructure solution was mixed with dimethyl sulfoxide (DMSO, $0.1 \mathrm{~mL}$ ), and sonicated for $30 \mathrm{~min}$ to dissolve the loaded drug. After centrifugation $(12000 \mathrm{~g}, 10 \mathrm{~min}$ ) of this solution, the GA concentration of the supernatant was determined according to the standard curve using an Agilent 6230 time-of-flight (TOF) liquid chromatography-mass spectrometry (LC/MS) system. The drug loading capacity was then calculated.

\subsection{Drug desorption tests}

GA desorption from GA-loaded $\mathrm{GNR} / \mathrm{TiO}_{2}$ nanostructures was studied in $\mathrm{NaOH}(0.1 \mathrm{M})$, PBS (pH 7.4), or citrate buffer (20 mM, $\mathrm{pH}$ 4.5). The GA-loaded $\mathrm{GNR} / \mathrm{TiO}_{2}$ nanostructures $(15 \mu \mathrm{g} \mathrm{Au}$ $\left.\mathrm{mL}^{-1}\right)$ were dispersed in the buffer $(1 \mathrm{~mL})$ at $37{ }^{\circ} \mathrm{C}$ for $24 \mathrm{~h}$. After centrifugation $(12000 \mathrm{rpm}, 10 \mathrm{~min})$, the supernatant was collected, and the released GA in the supernatant was extracted three times using chloroform $(0.5 \mathrm{~mL})$. After the solvent was evaporated, the residual GA was dissolved with methanol $(50 \mu \mathrm{L})$, and the GA concentration was determined using LC/MS. The drug desorption percentage was then calculated.

\subsection{Intracellular GA content assay}

U-87 MG cells were cultured in $100 \mathrm{~mm}$ Petri dishes. When the cells reached $80 \%$ confluence, the culture medium was replaced with a fresh medium containing the GA-loaded $\mathrm{GNR} / \mathrm{TiO}_{2}$ nanostructures or free GA at the equal GA concentration of 0.27 $\mu \mathrm{M}$. After incubation for $24 \mathrm{~h}$, the cells were washed with PBS, collected and counted. The cells were subsequently centrifuged at $4500 \mathrm{~g}$ for $5 \mathrm{~min}$. DMSO $(0.1 \mathrm{~mL})$ was used to extract the GA from the cell pellets. After centrifugation (12 000g, $10 \mathrm{~min}$ ), the supernatant was collected and the GA concentration was determined using LC/MS. The GA amount per cell was then calculated.

\subsection{Nuclei staining}

After the U-87 MG cells were incubated with the GA-loaded $\mathrm{GNR} / \mathrm{TiO}_{2}$ nanostructures or free GA for $24 \mathrm{~h}$, the cells were washed with PBS to remove any nanoparticles adsorbed on the cell surface. The nuclei of the cells were subsequently stained with Hoechst 33342 (100 ng mL ${ }^{-1}$, Thermo Fisher Scientific) for $30 \mathrm{~min}$, and the cells were observed on an Olympus IX71 microscope.

\subsection{Photothermal therapy}

Five thousand U-87 MG cells were seeded into each well of a 96-well plate. After incubation for $24 \mathrm{~h}$, the culture medium was changed with phenol red-free $\alpha$-MEM $(100 \mu \mathrm{L})$ containing GA
$(0.27 \mu \mathrm{M}), \mathrm{GNR} / \mathrm{TiO}_{2}$ nanostructures $\left(12.5 \mu \mathrm{g} \mathrm{Au} \mathrm{mL}^{-1}\right)$, or GA loaded $\mathrm{GNR} / \mathrm{TiO}_{2}$ nanostructures $\left(0.27 \mu \mathrm{M} \mathrm{GA}, 12.5 \mu \mathrm{g} \mathrm{Au} \mathrm{mL}{ }^{-1}\right)$, followed by further incubation for $24 \mathrm{~h}$. The designated wells were exposed to a continuous-wave semiconductor diode laser (808 nm, MDL-N-808-10W, Changchun New Industries Optoelectronics Tech. Co., Ltd., China) for $2 \mathrm{~min}$. The laser power density was $4.4,5.3,6.2$ or $7.9 \mathrm{~W} \mathrm{~cm}^{-2}$, and the laser spot diameter was $\sim 6 \mathrm{~mm}$, which is equal to the diameter of the bottom of a well on the 96-well plate. The cells were incubated for another $24 \mathrm{~h}$, and ATP assay and calcein acetoxymethyl ester (calcein AM) staining were separately performed to determine the cell viability. After the treatment, the medium in the wells was replaced with serum-free $\alpha$-MEM containing calcein AM ( $1 \mu \mathrm{M}$, Thermo Fisher Scientific). After incubation for $30 \mathrm{~min}$, the cells were washed with fresh medium, and an Olympus IX71 microscope was used to capture images.

\subsection{Statistical analysis}

Each experiment was repeated at least 3 times. Data are expressed as mean \pm standard error of the mean (S.E.M.). The statistical difference was evaluated with one-way analysis of variance (ANOVA) followed by Tukey's post hoc test. A $P$ value $<0.05$ was considered as statistically significant.

\section{Results and discussion}

\subsection{Synthesis and characterization of the $\mathrm{GNR} / \mathrm{TiO}_{2}$ nanostructures}

GNR/CTAB nanostructures were prepared using a seedmediated growth method. ${ }^{28}$ Transmission electron microscopy (TEM) imaging showed rod shapes with a narrow size distribution (Fig. 1a). The length and diameter of the GNRs were determined to be $90 \pm 4 \mathrm{~nm}$ and $29 \pm 2 \mathrm{~nm}$, respectively (Fig. 1a). The zeta potential of the GNR/CTAB nanostructures was found to be $+47 \pm 7 \mathrm{mV}$. The GNRs were found to support two plasmon modes, a longitudinal and a transverse mode. ${ }^{20}$
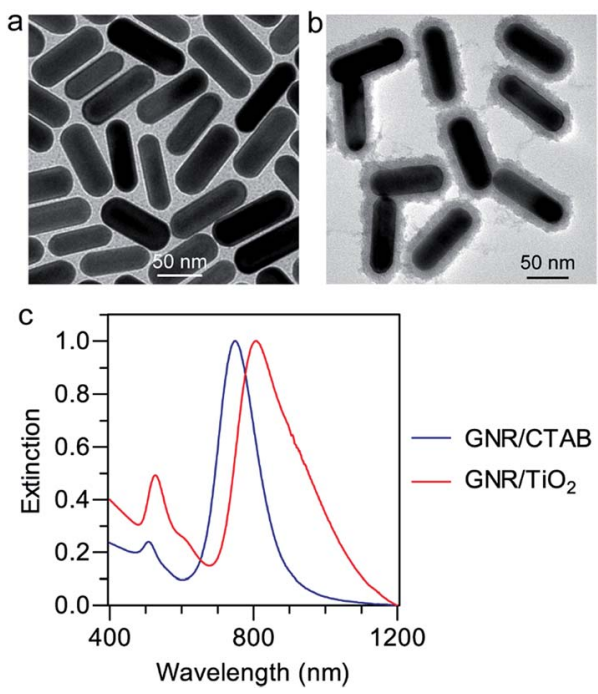

Fig. 1 TEM images of GNR/CTAB (a) and $\mathrm{GNR} / \mathrm{TiO}_{2}$ (b) nanostructures, and (c) extinction spectra of the synthesized nanostructures. 
The extinction spectrum of the GNR/CTAB in aqueous solution (Fig. 1c) shows that the longitudinal and transverse plasmon resonance peaks are located at $742 \mathrm{~nm}$ and $526 \mathrm{~nm}$, respectively. The $\mathrm{GNR} / \mathrm{TiO}_{2}$ nanostructures were prepared by employing $\mathrm{TiCl}_{3}$ as the precursor. ${ }^{28}$ The zeta potential of the $\mathrm{GNR} / \mathrm{TiO}_{2}$ sample was determined to be $-2 \pm 2 \mathrm{mV}$. The $\mathrm{TiO}_{2}$ coating with a thickness of $12 \pm 1 \mathrm{~nm}$ (Fig. 1b) induces a considerable red shift of the longitudinal plasmon resonance wavelength (LPRW) to $806 \mathrm{~nm}$ (Fig. 1c), which is within the biological window of $650-900 \mathrm{~nm} .{ }^{21}$ In addition, the hydrodynamic diameter of the GNR/TiO ${ }_{2}$ nanostructures, measured by the dynamic light scattering technique, is $102 \pm 18 \mathrm{~nm}$. After incubation with the culture medium for $12 \mathrm{~h}$, the size was determined to be $105 \pm 21 \mathrm{~nm}$, thus indicating that no particle aggregation occurred in the culture medium.

\subsection{Photothermal conversion of the $\mathrm{GNR} / \mathrm{TiO}_{2}$ nanostructures}

Plasmonic gold nanostructures can absorb light and convert it into heat when irradiated with an NIR laser. This heat is thereafter transferred to the surrounding environment to cause a temperature increase. Gold nanostructure-based photothermal therapy has been previously employed to selectively ablate cancer cells, ${ }^{30}$ and trigger drug $^{31}$ or gene release. ${ }^{32,33}$ Generally, due to their higher photothermal conversion efficiency, gold nanostructures can cause an equal degree of cancer cell death at a lower concentration, a shorter irradiation time, and a lower laser power density. A high photothermal conversion efficiency of gold nanostructures is essential for achieving photothermal therapeutic effects.

To measure the photothermal conversion performance of the $\mathrm{GNR} / \mathrm{TiO}_{2}$ nanostructures, radiation from an $808 \mathrm{~nm}$ laser was sent through a quartz cuvette with a $1 \mathrm{~cm}$ path length containing an aqueous $\mathrm{GNR} / \mathrm{TiO}_{2}$ nanostructure dispersion (50 $\mu \mathrm{g} \mathrm{Au} \mathrm{mL} \mathrm{m}^{-1}, 2 \mathrm{~mL}$ ). The optical extinction of the dispersion at $808 \mathrm{~nm}$ was adjusted to 2.0 , and a thermocouple was inserted into the aqueous dispersion at such a position that the direct irradiation of the laser on the probe was avoided. The temperature was recorded every $30 \mathrm{~s}$ after the laser had been turned on for $30 \mathrm{~min}$ until the temperature of the $\mathrm{GNR} / \mathrm{TiO}_{2}$ nanostructure dispersion solution reached a steady state. The solution was kept stirring during the measurements. The laser was then switched off and the temperature decrease profile was recorded to determine the rate of the heat transfer from the system to the environment. Fig. 2a shows the temperature rise traces of the $\mathrm{GNR} / \mathrm{TiO}_{2}$ nanostructures under $808 \mathrm{~nm}$ laser irradiation. The temperature increases rapidly in the beginning and then reaches a plateau after about $20 \mathrm{~min}$ of irradiation. After irradiation for 30 min with the $808 \mathrm{~nm}$ laser at a power of $1.4 \mathrm{~W}$, the end temperature reaches $57.1^{\circ} \mathrm{C}$ (Fig. 2b).

A previously-reported theoretical model ${ }^{29}$ was used to determine the photothermal conversion efficiency $\eta$ according to the following eqn (1):

$$
\eta=\frac{B\left(T_{\text {end }}-T_{0}\right)+C\left(T_{\text {end }}-T_{0}\right)^{2}-I \xi}{I(1-\xi)\left(1-10^{-E}\right)}
$$

where $I=0.6,1.0$ or $1.4 \mathrm{~W}$ is the laser output power value, and $E$ is the extinction value at $808 \mathrm{~nm}$, which has been adjusted to 2.0. $B$ and $C$ are two coefficients characterizing the temperaturedependent thermal loss of the entire system. They can be determined by fitting the temperature decay curve (Fig. 2c). The determined $B$ and $C$ values are $1.876 \mathrm{~J} \mathrm{~K}^{-1} \mathrm{~min}^{-1}$ and $0.00352 \mathrm{~J}$ $\mathrm{K}^{-2} \min ^{-1}$, respectively. $T_{0}$ is the temperature of the solution before the laser irradiation, and $T_{\text {end }}$ is the steady temperature reached under the laser irradiation. $\xi$ is the fraction of the laser energy absorbed by the cuvette walls and the solution, which was determined to be 0.0411 by measuring the temperature rise and decay curves of pure water. According to eqn (1), we obtained a photothermal conversion efficiency of $85.3 \pm 4.4 \%$ for the $\mathrm{GNR} / \mathrm{TiO}_{2}$ nanostructures under the $808 \mathrm{~nm}$ laser irradiation.

\subsection{Cellular uptake and cytotoxicity of the $\mathrm{GNR} / \mathrm{TiO}_{2}$ nanostructures}

As an anticancer drug carrier, efficient internalization by cancer cells and biocompatibility should be considered to be of utmost importance. ${ }^{34,35}$ Glioblastoma is one of the most aggressive cancers, and the anticancer effect of GA on glioblastoma has attracted increasing attention. ${ }^{1}$ In this study, cellular uptake and cytotoxicity of $\mathrm{GNR} / \mathrm{TiO}_{2}$ nanostructures were studied in human glioblastoma U-87 MG cells. Bright field imaging under an inverted microscope was used as a simple method to
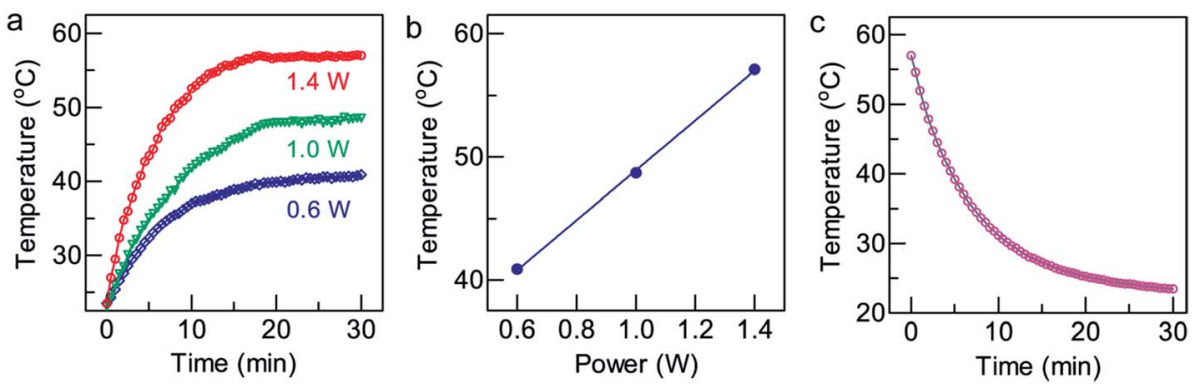

Fig. 2 Photothermal conversion of $\mathrm{GNR} / \mathrm{TiO}_{2}$ nanostructures. (a) Temperature rise curves of the $\mathrm{GNR} / \mathrm{TiO} \mathrm{O}_{2}$ nanostructures in water $(50 \mu \mathrm{g} \mathrm{Au}$ $\mathrm{mL}^{-1}, 2 \mathrm{~mL}$ ) acquired under $808 \mathrm{~nm}$ laser irradiation at various laser powers for $30 \mathrm{~min}$. (b) Plateau temperatures reached as a function of the laser power. (c) Temperature decay. The data points were measured during the cooling process after the $\mathrm{GNR}_{\mathrm{TiO}} \mathrm{T}_{2}$ nanostructure solution $(50 \mu \mathrm{g}$ Au $\mathrm{mL}^{-1}, 2 \mathrm{~mL}$ ) was irradiated with the $808 \mathrm{~nm}$ laser at $1.4 \mathrm{~W}$ for $30 \mathrm{~min}$. The blue line was obtained from fitting. 
a

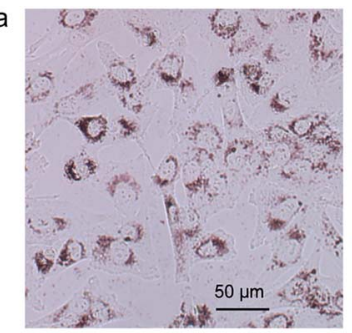

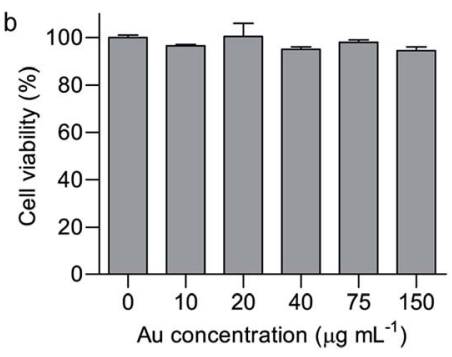

Fig. 3 Cellular uptake and cytotoxicity of $\mathrm{GNR} / \mathrm{TiO}_{2}$ nanostructures (a) Bright field imaging of U-87 MG cells after incubation with GNR/ $\mathrm{TiO}_{2}$ nanostructures $\left(30 \mu \mathrm{g} \mathrm{Au} \mathrm{mL}{ }^{-1}\right)$. Dark red $\mathrm{GNR} / \mathrm{TiO}_{2}$ granules are evident in the cytoplasm around the nuclei of cells. (b) Effect of GNR/ $\mathrm{TiO}_{2}$ nanostructures on U-87 MG cell viability. U-87 MG cells were exposed to varying concentrations $\left(0-150 \mu \mathrm{g} \mathrm{Au} \mathrm{mL}{ }^{-1}\right)$ of $\mathrm{GNR} / \mathrm{TiO}_{2}$ nanostructures for $48 \mathrm{~h}$, followed by an ATP assay. The data shown represent the mean \pm S.E.M.

evaluate the cellular uptake of $\mathrm{GNR} / \mathrm{TiO}_{2}$ nanostructures, and they show a dark red color. As shown in Fig. 3a, the GNR/TiO nanostructures are readily internalized by U-87 MG cells, and most of the nanostructures were observed in the cytoplasm around the nuclei. In addition, endosome/lysosome staining with LysoSensor Green (Fig. S1†) shows that internalized $\mathrm{GNR} / \mathrm{TiO}_{2}$ nanostructures are mainly located in the endosomes/ lysosomes. After treatment for 48 hours with the $\mathrm{GNR} / \mathrm{TiO}_{2}$

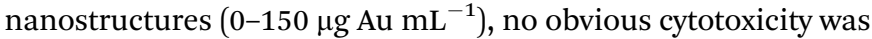
observed in the U-87 MG cells (Fig. 3b), indicating that the $\mathrm{GNR} / \mathrm{TiO}_{2}$ nanostructures are biocompatible.

\subsection{Photothermal therapy study}

Hyperthermia induces cell death at temperatures above $43{ }^{\circ} \mathrm{C} .{ }^{36}$ Compared with common hyperthermia therapy, photothermal therapy is able to noninvasively and selectively ablate cancer cells. Efficient light absorption and photothermal conversion in the NIR region enables GNRs to denature cell proteins and therefore cause irreversible cell death upon light irradiation. ${ }^{37}$ Nanostructure-based photothermal therapeutic effects have previously been found to be highly dependent on the irradiation power density and duration. In this study, solo irradiation with the $808 \mathrm{~nm}$ laser at the power density of $7.9 \mathrm{~W} \mathrm{~cm}^{-2}$ for $2 \mathrm{~min}$ did not affect the cell viability of U-87 MG cells. Irradiation with the $808 \mathrm{~nm}$ laser for $2 \mathrm{~min}$ at the power density of 6.2 and $7.9 \mathrm{~W}$ $\mathrm{cm}^{-2}$ in the presence of the $\mathrm{GNR} / \mathrm{TiO}_{2}$ nanostructures reduced the cell viability of U-87 MG cells to $48.7 \pm 5.2 \%$ and $25.0 \pm$ $6.1 \%$, respectively (Fig. 4a). In addition, calcein AM staining was also used to confirm this result. Calcein AM can reveal the ubiquitous intracellular esterase activity inside live cells, and therefore only live cells are stained with green fluorescence. ${ }^{38}$ Most cells in the control group display green fluorescence and maintain their normal morphology. In contrast, rounding of the cell morphology was clearly observed for the cells after laser irradiation at $6.2 \mathrm{~W} \mathrm{~cm}{ }^{-2}$ in the presence of the $\mathrm{GNR} / \mathrm{TiO}_{2}$ nanostructures. The green fluorescence was almost undetectable after laser irradiation at $7.9 \mathrm{~W} \mathrm{~cm}^{-2}$, indicating that the irradiation power density of $7.9 \mathrm{~W} \mathrm{~cm}^{-2}$ is able to kill most of the U-87 MG cells (Fig. 4b). A low irradiation dose $\left(5.3 \mathrm{~W} \mathrm{~cm}^{-2}\right.$, $2 \mathrm{~min}$ ) was chosen in the following experiments.

\subsection{Loading GA onto $\mathrm{GNR} / \mathrm{TiO}_{2}$ nanostructures}

Carboxylic acid has a high binding affinity to $\mathrm{TiO}_{2},{ }^{27}$ so we then tried to use the $\mathrm{GNR} / \mathrm{TiO}_{2}$ nanostructures as the delivery carrier for the GA molecule, which has a carboxylic group (Fig. 5a). The drug loading was performed in ethanol. The obtained GAloaded $\mathrm{GNR} / \mathrm{TiO}_{2}$ nanostructures were well dispersible in water (Fig. 5b). The GA loading capacity of the $\mathrm{GNR} / \mathrm{TiO}_{2}$ nanostructures was calculated to be $1.33 \pm 0.1 \%$, according to the following eqn (2).

$$
\text { Loading capacity }=\frac{\text { weight of } \mathrm{GA} \text { in } \mathrm{GNR} / \mathrm{TiO}_{2}}{\text { weight of the } \mathrm{GNR} / \mathrm{TiO}_{2}} \times 100 \%
$$

Alkaline solutions are effective agents for desorbing carboxylic acid molecules from the surface of $\mathrm{TiO}_{2} \cdot{ }^{39,40}$ To evaluate the binding between GA and $\mathrm{TiO}_{2}$, GA-loaded $\mathrm{GNR} / \mathrm{TiO}_{2}$ nanostructures were immersed in a basic aqueous solution $(\mathrm{NaOH}, 0.1$
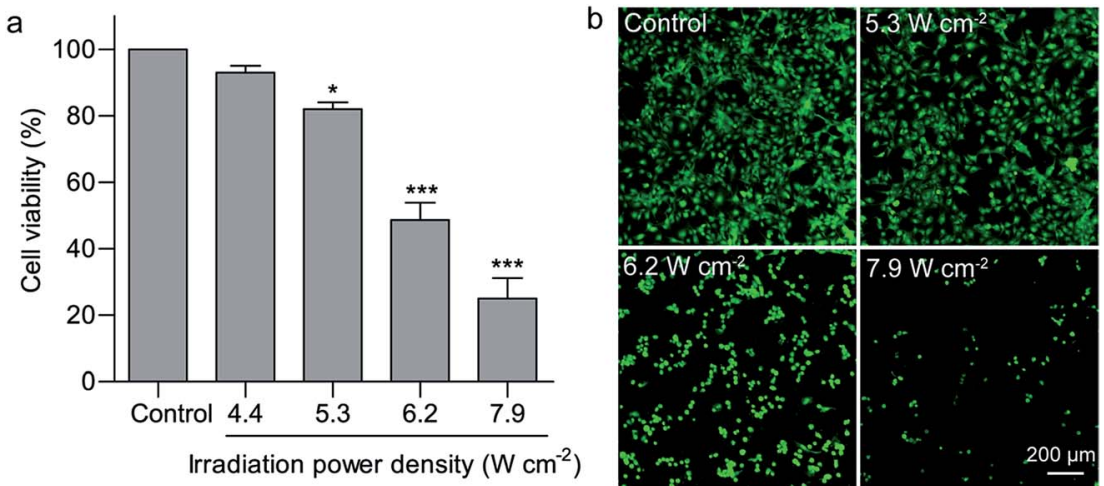

Fig. 4 Cell viability of U-87 MG cells upon photothermal therapy. U-87 MG cells were incubated with the $\mathrm{GNR}^{-2} \mathrm{TiO}_{2}$ nanostructures at the concentration of $12.5 \mu \mathrm{g} \mathrm{Au} \mathrm{mL}^{-1}$ for $24 \mathrm{~h}$, followed by $808 \mathrm{~nm}$ NIR laser irradiation at 4.4, 5.3, 6.2 or $7.9 \mathrm{~W} \mathrm{~cm}^{-2}$ for 2 min. The cell viability was determined by (a) ATP assay or (b) calcein AM staining after further incubation for $24 \mathrm{~h}$. Live cells were stained with green fluorescence by calcein AM. The data shown represent the mean \pm S.E.M., $* P<0.05, * * * P<0.001$ 
a

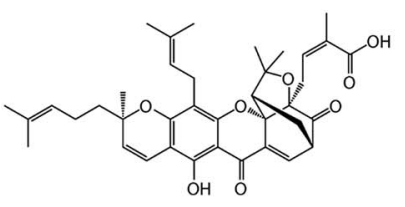

Gambogic acid (GA) b

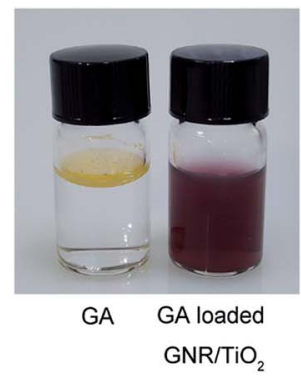

C

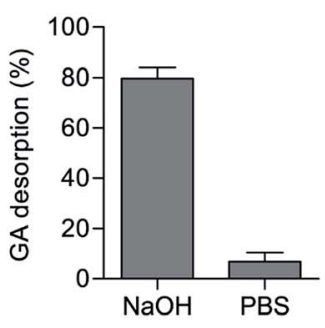

Fig. 5 GA loading. (a) Chemical structure of GA. (b) GA and GA-loaded GNR/TiO 2 suspensions in water. (c) Desorption of GA in NaOH and PBS.

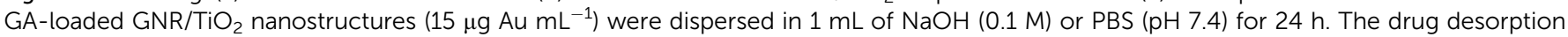
percentage was calculated by measuring the drug concentration of the supernatant. The data shown represent the mean \pm S.E.M.

M) for 24 h. $79.6 \pm 4.3 \%$ of GA was stripped from the $\mathrm{TiO}_{2}$ surfaces as shown in Fig. $5 c$. However, only $6.8 \pm 3.7 \%$ of GA desorbed from the $\mathrm{GNR} / \mathrm{TiO}_{2}$ nanostructures in PBS ( $\mathrm{pH}$ 7.4). We assumed that the dramatic GA desorption in the $\mathrm{NaOH}$ solution is due to the carboxylic acid group of GA reacting with $\mathrm{NaOH}$ and it being converted into a water-soluble salt. As the internalized nanoparticles are mainly distributed in the acidic endosomes/ lysosomes, we also studied the GA desorption in endosome/ lysosome mimicking buffer (20 mM citrate, $\mathrm{pH} 4.5) .{ }^{41} 18.6 \pm$ $3.1 \%$ of GA released from the GA-loaded $\mathrm{GNR} / \mathrm{TiO}_{2}$ nanostructures was observed after incubation for $24 \mathrm{~h}$. This result is attributed to the fact that citric acid is able to competitively displace GA from the $\mathrm{GNR} / \mathrm{TiO}_{2}$ nanostructures, as it also has carboxylic acid groups.

\subsection{Enhanced cytotoxicity of the GA-loaded $\mathrm{GNR} / \mathrm{TiO}_{2}$ nanostructures}

As the $\mathrm{GNR} / \mathrm{TiO}_{2}$ nanostructures are readily internalized by $\mathrm{U}-87$ MG cells, we speculated that the $\mathrm{GNR} / \mathrm{TiO}_{2}$ nanostructures are able to carry more GA into these cells than free GA. We compared the intracellular GA content of the cells treated with free GA and those treated with the GA-loaded $\mathrm{GNR} / \mathrm{TiO}_{2}$ nanostructures at the same drug concentration. After GA was extracted from the cells with the organic solvent, the GA concentration was analyzed using LC/MS, which is suitable for detecting GA at a very low concentration range. As shown in Fig. 6a, after incubation of $0.27 \mu \mathrm{M}$ GA for $24 \mathrm{~h}$, the intracellular GA content of cells that underwent the free-form treatment was $(9.6 \pm 2.2) \times 10^{-17} \mathrm{~g}$ per cell. On the other hand, this value was determined to be $(6.0 \pm 0.7) \times 10^{-16} \mathrm{~g}$ per cell for the GA-loaded $\mathrm{GNR} / \mathrm{TiO}_{2}$ nanostructure treatment group $(P<0.001)$. This result indicated that the $\mathrm{GNR} / \mathrm{TiO}_{2}$ nanostructures can increase the concentration of GA in the cancer cells compared with the free form, and therefore, they offer the possibility of higher therapeutic efficacy.

The cytotoxic effect of the GA-loaded $\mathrm{GNR}^{\mathrm{TiO}} \mathrm{T}_{2}$ nanostructures was also compared with that of the free GA. Both GA and the GA-loaded $\mathrm{GNR} / \mathrm{TiO}_{2}$ nanostructures showed an apparent dose-dependent cytotoxicity in U-87 MG cells, as shown in Fig. 6b. Enhanced cytotoxicity was achieved by using $\mathrm{GNR} / \mathrm{TiO}_{2}$ nanostructure-based intracellular delivery. After incubation for $48 \mathrm{~h}$ with $1 \mu \mathrm{M}$ GA, the cell viability of the U-87 MG cells was $84.7 \pm 5.2 \%$. However, for the cells treated with the GA-loaded $\mathrm{GNR} / \mathrm{TiO}_{2}$ nanostructures at the same drug concentration, the cell viability was reduced to $41.0 \pm 5.2 \%$ $(P<0.001)$. We further used a cell-permeable DNA dye, Hoechst 33342 , to stain the DNA of the cells. The GA-loaded GNR/TiO nanostructures $(0.33 \mu \mathrm{M}$ GA, $24 \mathrm{~h})$ caused cell shrinkage with an intact cell membrane, chromosome condensation and DNA fragmentation (Fig. 6c). No lactate dehydrogenase (LDH) was detected in the culture medium. These results indicate that cell apoptosis rather than necrosis was induced by the GA-loaded GNR/ $/ \mathrm{TiO}_{2}$ nanostructures. However, U-87 MG cells treated
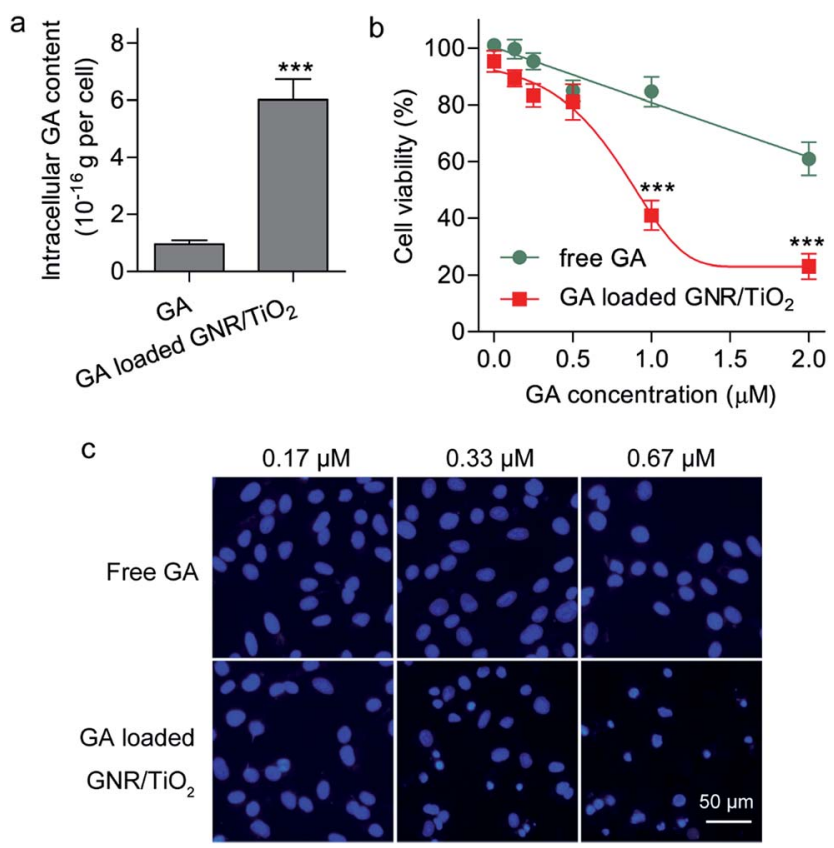

Fig. 6 Comparison of the cytotoxic effects of free GA and GA-loaded GNR/TiO 2 nanostructures. (a) Intracellular GA content. U-87 MG cells were treated with free $\mathrm{GA}$ or $\mathrm{GA}$-loaded $\mathrm{GNR} / \mathrm{TiO} \mathrm{O}_{2}$ nanostructures at a GA concentration of $0.27 \mu \mathrm{M}$ for $24 \mathrm{~h}$, and the intracellular GA content was determined using LC/MS. (b) Effect of GA-loaded GNR/ $\mathrm{TiO}_{2}$ nanostructures and free GA on cell viability of U-87 MG cells. U-87 MG cells were treated with free GA or GA-loaded $\mathrm{GNR} / \mathrm{TiO}_{2}$ nanostructures at various GA concentrations for $48 \mathrm{~h}$, followed by ATP assay. (c) Effect of GA-loaded $\mathrm{GNR} / \mathrm{TiO}_{2}$ nanostructures and free GA on DNA fragmentation in U-87 MG cells. After incubation for $24 \mathrm{~h}$, the cells were stained with $100 \mathrm{ng} \mathrm{mL}^{-1}$ Hoechst 33342. The data shown represent the mean \pm S.E.M., $* * * P<0.001$. 
a

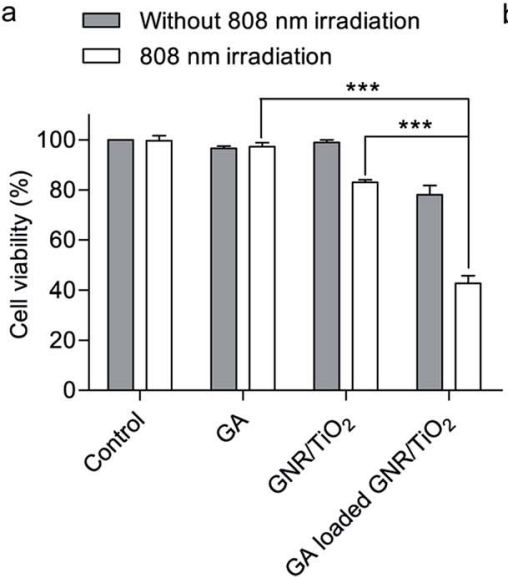

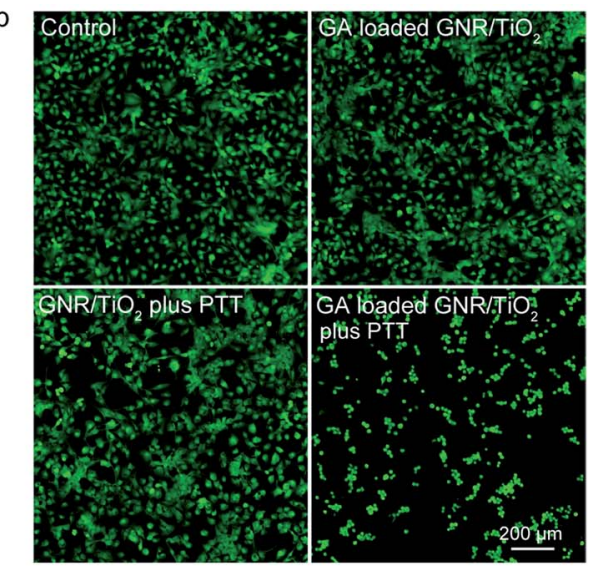

Fig. 7 Enhanced cytotoxic effect of $\mathrm{GA}$ by using $\mathrm{GNR} / \mathrm{TiO}_{2}$ nanostructure-mediated photothermal therapy. U-87 MG cells were incubated with $\mathrm{GNR} / \mathrm{TiO}_{2}$ or GA-loaded $\mathrm{GNR} / \mathrm{TiO}_{2}$ nanostructures at the GA concentration of $0.27 \mu \mathrm{M}$ for $24 \mathrm{~h}$, followed by $808 \mathrm{~nm} \mathrm{NIR} \mathrm{irradiation} \mathrm{(5.3} \mathrm{W} \mathrm{cm}^{-2}$ ) for 2 min. After incubation for $24 \mathrm{~h}$, cell viability was determined using an ATP assay (a) and calcein AM staining (b). Live cells were stained with green fluorescence by calcein AM. The data shown represent the mean \pm S.E.M., ***P<0.001.

with free GA $(0.67 \mu \mathrm{M})$ showed an intact nuclear architecture (Fig. 6c). A similar result was obtained in one of our previous studies, where enhanced cellular uptake and cytotoxicity of hydrophobic anticancer drugs were achieved by using hollow superparamagnetic iron oxide (SPIO) nanoshells as the drug carrier. ${ }^{41}$ These results suggest that owing to the ability of the $\mathrm{GNR} / \mathrm{TiO}_{2}$ nanostructures to carry more drug into the cells, they significantly enhance the cytotoxicity of GA.

\subsection{Photothermal therapy-enhanced cytotoxicity of GA}

In some cases, hyperthermia therapy is performed at a moderately elevated temperature, ${ }^{42}$ and it synergistically enhances the anticancer effects of chemotherapeutic agents. ${ }^{43,44}$ The results from a recent clinical study indicate that a combination of hyperthermia and chemotherapy results in a higher survival rate for the nonmuscle-invasive bladder cancer patients. ${ }^{45}$ The photothermal therapy-mediating agents encapsulated with anticancer drugs can deliver both drugs and heat simultaneously to the tumor. This multi-modal treatment strategy can result in additionally enhanced anticancer efficacy ${ }^{46}$ The mechanisms for chemosensitization with hyperthermia include enhanced reactive oxygen species production, inhibition of DNA repair, and increased intracellular drug accumulation. ${ }^{42}$

In this regard, we examined the efficacy of $\mathrm{GNR} / \mathrm{TiO}_{2}$ nanostructure-mediated photothermal therapy in combination with GA. Here, a low irradiation dose $\left(5.3 \mathrm{~W} \mathrm{~cm}^{-2}, 2 \mathrm{~min}\right)$ and a low GA dose $(0.27 \mu \mathrm{M}, 48 \mathrm{~h})$ were used in this experiment. The cell viabilities after these two treatments were $96.7 \pm 0.9 \%$ and $97.3 \pm 0.9 \%$, respectively (Fig. 7a). The GA-loaded $\mathrm{GNR} / \mathrm{TiO}_{2}$ nanostructures $(0.27 \mu \mathrm{M} \mathrm{GA}, 48 \mathrm{~h})$ slightly reduced the viability to $78.0 \pm 3.8 \%$. GNR/ $/ \mathrm{TiO}_{2}$ nanostructure-based photothermal therapy at the same irradiation dose $\left(5.3 \mathrm{~W} \mathrm{~cm}^{-2}, 2 \mathrm{~min}\right)$ also reduced the cell viability to $83.3 \pm 0.6 \%$. However, a combination of the GA-loaded $\mathrm{GNR} / \mathrm{TiO}_{2}$ nanostructures and photothermal therapy reduced the cell viability to $42.7 \pm 1.8 \%$ in a synergistic manner (Fig. 7a). This result was also confirmed by calcein AM staining. Almost all of the cells became rounded and green fluorescence was not detectable for most cells after the combined treatment. In contrast, most cells after receiving the monotherapy alone displayed green fluorescence and maintained their normal morphology (Fig. 7b). Our results indicate that the application of $\mathrm{GNR} / \mathrm{TiO}_{2}$ nanostructure-based photothermal therapy synergistically enhances the anticancer effect of GA.

Chemotherapy dose has a direct impact on cancer patient outcomes. ${ }^{47}$ Although the risk of toxicity from intensive chemotherapy should be considered, inadequate treatment that might induce tumor recurrence should be avoided. In view of this fact, the incorporation of $\mathrm{GNR} / \mathrm{TiO}_{2}$ nanostructure-mediated photothermal therapy with chemotherapy will be useful for improving the efficacy of GA. This combined treatment provides the possibility of reducing the GA dosage or achieving enhanced anticancer effects.

\section{Conclusions}

In summary, $\mathrm{GNR} / \mathrm{TiO}_{2}$ nanostructures as an intracellular carrier for GA were reported for the first time. This delivery approach provides a stable aqueous dispersion of GA. Compared with the free $\mathrm{GA}$, the GA-loaded $\mathrm{GNR} / \mathrm{TiO}_{2}$ nanostructures induce a higher intracellular GA content and superior cytotoxicity. In addition, the $\mathrm{GNR} / \mathrm{TiO}_{2}$ nanostructures show a high photothermal conversion efficiency under $808 \mathrm{~nm}$ NIR laser irradiation. Photothermal therapy at a low irradiation dose $\left(5.3 \mathrm{~W} \mathrm{~cm}^{-2}, 2 \mathrm{~min}\right)$ further synergistically enhances the anticancer effects of the GA-loaded $\mathrm{GNR} / \mathrm{TiO}_{2}$ nanostructures. Our results suggest that the GNR/ $\mathrm{TiO}_{2}$ nanostructures will offer great potential for GA delivery.

\section{Conflicts of interest}

The authors declare no competing financial interests.

\section{Acknowledgements}

This work was supported by Macau Science and Technology Development Fund (Project No. 014/2014/A1). 


\section{References}

1 L. Qiang, Y. Yang, Q.-D. You, Y.-J. Ma, L. Yang, F.-F. Nie, H.-Y. Gu, L. Zhao, N. Lu, Q. Qi, W. Liu, X.-T. Wang and Q.-L. Guo, Biochem. Pharmacol., 2008, 75, 1083-1092.

2 L.-H. Wang, Y. Li, S.-N. Yang, F.-Y. Wang, Y. Hou, W. Cui, K. Chen, Q. Cao, S. Wang, T.-Y. Zhang, Z.-Z. Wang, W. Xiao, J.-Y. Yang and C.-F. Wu, Br. J. Cancer, 2014, 110, 341-352.

3 D. Z. Duan, B. X. Zhang, J. Yao, Y. P. Liu, J. Y. Sun, C. P. Ge, S. J. Peng and J. G. Fang, Free Radical Biol. Med., 2014, 69, 15-25.

4 L. L. Liang and Z. X. Zhang, Cell. Physiol. Biochem., 2016, 38, 1618-1630.

5 X. P. Shi, X. Chen, X. F. Li, X. Y. Lan, C. Zhao, S. T. Liu, H. B. Huang, N. N. Liu, S. Y. Liao, W. B. Song, P. Zhou, S. Q. Wang, L. Xu, X. J. Wang, Q. P. Dou and J. B. Liu, Clin. Cancer Res., 2014, 20, 151-163.

6 P. van Hoogevest, X. L. Liu and A. Fahr, Expert Opin. Drug Delivery, 2011, 8, 1481-1500.

7 N. Bertrand, J. Wu, X. Y. Xu, N. Kamaly and O. C. Farokhzad, Adv. Drug Delivery Rev., 2014, 66, 2-25.

8 I.-P. Huang, S.-P. Sun, S.-H. Cheng, C.-H. Lee, C.-Y. Wu, C.-S. Yang, L.-W. Lo and Y.-K. Lai, Mol. Cancer Ther., 2011, 10, 761-769.

9 X. W. Dong, C. A. Mattingly, M. T. Tseng, M. J. Cho, Y. Liu, V. R. Adams and R. J. Mumper, Cancer Res., 2009, 69, 3918-3926.

10 M. R. Green, G. M. Manikhas, S. Orlov, B. Afanasyev, A. M. Makhson, P. Bhar and M. J. Hawkins, Ann. Oncol., 2006, 17, 1263-1268.

11 E. Miele, G. P. Spinelli, E. Miele, F. Tomao and S. Tomao, Int. J. Nanomed., 2009, 4, 99-105.

12 W. Z. Huang, X. Wang, C. Y. Shi, D. D. Guo, G. F. Xu, L. L. Wang, A. Bodman and J. T. Luo, Mol. Pharmaceutics, 2015, 12, 1216-1229.

13 G. W. Qu, X. Zhu, C. Zhang and Q. N. Ping, Drug Delivery, 2009, 16, 363-370.

14 L. L. Cai, N. Qiu, M. L. Xiang, R. S. Tong, J. F. Yan, L. He, J. Y. Shi, T. Chen, J. L. Wen, W. W. Wang and L. J. Chen, Int. J. Nanomed., 2014, 9, 243-255.

15 Y. Ding, Y. Z. Wang, Y. Opoku-Damoah, C. Wang, L. J. Shen, L. F. Yin and J. P. Zhou, Biomaterials, 2015, 72, 90-103.

16 H. Gelderblom, J. Verweij, K. Nooter and A. Sparreboom, Eur. J. Cancer, 2001, 37, 1590-1598.

17 S. Her, D. A. Jaffray and C. Allen, Adv. Drug Delivery Rev., 2017, 109, 84-101.

18 A. M. Alkilany, L. B. Thompson, S. P. Boulos, P. N. Sisco and C. J. Murphy, Adv. Drug Delivery Rev., 2012, 64, 190-199.

19 C. M. Cobley, J. Y. Chen, E. C. Cho, L. V. Wang and Y. N. Xia, Chem. Soc. Rev., 2011, 40, 44-56.

20 H. J. Chen, L. Shao, Q. Li and J. F. Wang, Chem. Soc. Rev., 2013, 42, 2679-2724.

21 R. A. Weissleder, Nat. Biotechnol., 2001, 19, 316-317.

22 J. B. Song, X. Y. Yang, O. Jacobson, L. S. Lin, P. Huang, G. Niu, Q. J. Ma and X. Y. Chen, ACS Nano, 2015, 9, 91999209.
23 J. F. Liao, W. T. Li, J. R. Peng, Q. Yang, H. Li, Y. Q. Wei, X. N. Zhang and Z. Y. Qian, Theranostics, 2015, 5, 345-356.

24 N. Larson, A. Gormley, N. Frazier and H. Ghandehari, J. Controlled Release, 2013, 170, 41-50.

25 J. Nowotny, M. A. Alim, T. Bak, M. A. Idris, M. Ionescu, K. Prince, M. Z. Sahdan, K. Sopian, M. A. Mat Teridi and W. Sigmund, Chem. Soc. Rev., 2015, 44, 8424-8442.

26 J. Schneider, M. Matsuoka, M. Takeuchi, J. L. Zhang, Y. Horiuchi, M. Anpo and D. W. Bahnemann, Chem. Rev., 2014, 114, 9919-9986.

27 Q. Y. Qu, H. W. Geng, R. X. Peng, Q. Cui, X. H. Gu, F. Q. Li and M. T. Wang, Langmuir, 2010, 26, 9539-9546.

28 X.-M. Zhu, C. H. Fang, H. L. Jia, Y. Huang, C. H. K. Cheng, C.-H. Ko, Z. Y. Chen, J. F. Wang and Y.-X. J. Wang, Nanoscale, 2014, 6, 11462-11472.

29 H. J. Chen, L. Shao, T. Ming, Z. H. Sun, C. M. Zhao, B. C. Yang and J. F. Wang, Small, 2010, 6, 2272-2280.

30 X. H. Huang, I. H. El-Sayed, W. Qian and M. A. El-Sayed, J. Am. Chem. Soc., 2006, 128, 2115-2120.

31 W.-H. Chen, C.-X. Yang, W.-X. Qiu, G.-F. Luo, H.-Z. Jia, Q. Lei, X.-Y. Wang, G. Liu, R.-X. Zhuo and X.-Z. Zhang, Adv. Healthcare Mater., 2015, 4, 2247-2259.

32 J. Song, K. Im, S. Hwang, J. Hur, J. Nam, G.-O. Ahn, S. Hwang, S. Kim and N. Park, Nanoscale, 2015, 7, 9433-9437.

33 A. M. Goodman, N. J. Hogan, S. Gottheim, C. Li, S. E. Clare and N. J. Halas, ACS Nano, 2017, 11, 171-179.

34 F. Zhao, Y. Zhao, Y. Liu, X. L. Chang, C. Y. Chen and Y. L. Zhao, Small, 2011, 7, 1322-1337.

35 B. Yameen, W. I. Choi, C. Vilos, A. Swami, J. J. Shi and O. C. Farokhzad, J. Controlled Release, 2014, 190, 485-499.

36 B. Hildebrandt, P. Wust, O. Ahlers, A. Dieing, G. Sreenivasa, T. Kerner, R. Felix and H. Riess, Crit. Rev. Oncol. Hematol., 2002, 43, 33-56.

37 E. B. Dickerson, E. C. Dreaden, X. H. Huang, I. H. El-Sayed, H. H. Chu, S. Pushpanketh, J. F. McDonald and M. A. ElSayed, Cancer Lett., 2008, 269, 57-66.

38 D. Gaspar, J. M. Freire, T. R. Pacheco, J. T. Barata and M. A. Castanho, Biochim. Biophys. Acta, 2015, 1853, 308-316.

39 H. K. Wayment-Steele, L. E. Johnson, F. Y. Tian, M. C. Dixon, L. Benz and M. S. Johal, ACS Appl. Mater. Interfaces, 2014, 6, 9093-9099.

40 D. H. Kim, M. D. Losego, K. Hanson, L. Alibabaei, K. Lee, T. J. Meyer and G. N. Parsons, Phys. Chem. Chem. Phys., 2014, 16, 8615-8622.

41 X.-M. Zhu, J. Yuan, K. C.-F. Leung, S.-F. Lee, K. W. Y. Sham, C. H. K. Cheng, D. W. T. Au, G.-J. Teng, A. T. Ahuja and Y.-X. J. Wang, Nanoscale, 2012, 4, 5744-5754.

42 M. Hurwitz and P. Stauffer, Semin. Oncol., 2014, 41, 714-729. 43 R. D. Issels, Eur. J. Cancer, 2008, 44, 2546-2554.

44 X.-M. Zhu, H.-Y. Wan, H. L. Jia, L. Liu and J. F. Wang, Adv. Healthcare Mater., 2016, 5, 3165-3172.

45 R. Colombo, A. Salonia, Z. Leib, M. Pavone-Macaluso and D. Engelstein, BJU Int., 2011, 107, 912-918.

46 M.-C. Chen, Z.-W. Lin and M.-H. Ling, ACS Nano, 2016, 10, 93-101.

47 G. H. Lyman, J. Natl. Compr. Cancer Network, 2009, 7, 99-108. 